\title{
On the Question of Conceptual Apparatus of Latin American Identity Discourse
}

\author{
Olga Bondar \\ Department of Social Philosophy \\ Faculty of Humanities and Social Sciences \\ Peoples' Friendship University of Russia \\ Miklukho-Maklay str., 10/2, Moscow, Russia, 117198 \\ E-mail: bondar_oyu@pfur.ru
}

\begin{abstract}
The author seeks to clarify the genesis of the conceptual apparatus of Latin American identity discourse within the "ontological stage" boundaries-i.e. the formation period of national concepts of world and a man. The author argues that the best way to discuss this issue is to investigate the dependence of the identification apparatus of historical and cultural context that influences the definitions included in it.
\end{abstract}

Keywords-identity discourse; marginality; borderline; the essence of America

\section{INTRODUCTION}

In modern-day Russian social science, the topic of Latin American self-identity discourse continues to be a subject of contextual discussions that include: literary, historical / historiographical, cultural, and philosophical ones. In Russian Latin American studies, the aforementioned topic and related issues are conceptualized in the works of Y.N. Girin, V.B. Zemskov, I.N. Ionov, B.I. Koval, A.F. Kofman, M.F. Nadyarnih, S.I. Semenov, and Y.G. Shemyakin. Despite the undeniable depth and fundamental research, the problem of defining the features of Latin American selfidentity discourse, its structural development logic and establishment of a conceptual apparatus ("alphabet") requires some clarification especially in respect to the apparatus that emerged later than the described period.

The assignment of Latin America to the borderline, i.e. non-classical civilization formations1, allowed the prospects

\footnotetext{
${ }^{1}$ In recent decades those invested in Latin American studies devote themselves to studying non-classical civilization formations, developing methodology for their systematic study. The basis for redirecting the research interest from classical to non-classical objects should be found in radical changes in socio-cultural and, respectively, cognitive structures that occurred in the second half of the $20^{\text {th }}$ century. Particularity of the emerged polycentric world was decisive in matters describing its existence and development, which, in turn, required a non-static approach to the research strategies.

The principles of unity - diversity and homogeneity - heterogeneity serve as basis of civilization formations division into classical and nonclassical ones. In this context, "the right", i.e. classical, object is not understood as the ideal essence expressed in the absolute homogeneity of its components. Heterogeneity and diversity are present in any civilization formation in the form of its cultural or ethno-cultural diversity. However, any system is the integrity of its diverse constituent elements. The feature
}

of its identity models, both internal and external formation, to be revealed. Representation of an external perspective "outside to inside" is a European discourse that expresses the desire to answer the question "What is America?" through the lens of a European perspective. This stage's chronological frame commenced in the 16th century-at the beginning of the New World exploration - and ended in the 1880s. Accordingly, an internal perspective, going "from inside", was represented by the actual (Latin) American 2 discourse centered on the question of the "essence of America and the American man". An integral part of the latter is a succession of its development stages from ontological to epistemological. Historical and cultural context has led to the inherent peculiarities, teleological load, problem field, and a set of interpretative schemes and models. As for the time interval, the ontological stage falls in 17 th century-turn of the 20th century. Emphasizing of the

of classical type formation is the principle of unity, which determines the prevalence of tendencies towards wholeness, the system's organic homogeneity. Intra-civilization space of such a system is stable and organically structured. An example to this formation principle can serve a monolithic religious-ideological foundation formed on the basis of the world's religions. Textbook examples of the classical type are: Western Christian, Indian, Chinese and Islamic civilizations.

In the Russian scientific tradition the classical civilization formations, that secured their supranational culture, or elaborated an independent world religion that incorporated philosophical traditions, had received the definition «culture subecumenism» [10. P. 205-227], [12. P. 64-68]. Nonclassical objects came to be defined as "borderline" ("splice", "liminal" (V. Turner), "peripheral"). They emerged on the periphery of major civilizations stable formations in transition, borderline, coupling zones of the latter [5. P. 96]. A distinct feature of such peripheral systems is the principle of heterogeneity. The tendencies to heterogeneity dominate in them. These formation designs are characterized by instability, heterogeneous, often cleaved, intra-civilization space with the religious and ideological formations being qualitatively different and sometimes contradicting to the basic ideas and attitudes. To this type count the Iberian, Balkan, Turkish, Russian and Latin American civilizations.

2 On the Insufficiency of the Definition "Latin American" cf. Bondar O.Y. Building self-identity models: Latin-American civilizational version. Part II // Bulletin of RUDN. "Philosophy” series. - №3. - 2014. - P. 120-134. 
epistemological period starts in the 1920s and spans till contemporary times.

\section{TO MECHANICS OF CULTURE GENESIS}

The situation of «historical pseudomorphosis» [13. P. 193-196] becomes defining the architecture of Latin American self-identity process. To the field of cultural and philosophical analysis, this definition was transferred from geology by Oswald Spengler. The German philosopher used the definition to describe the cultural interaction processes, similar, in his opinion, to those occurring in nature during the formation of rocks. Natural pseudomorphs are tumors that appear in an atypical form, resulting from a substitution process in which the appearance and dimensions remain constant, but the original mineral is replaced by another. As for the historical pseudomorphs, they appear as a result of such an interaction, when the participants - cultural horizons or civilizations - are initially unequal. During the pseudomorphosis process, historically immature and weak culture experiences the pressure, coming from a strong and historically consistent one, while undergoing warps and fissures of such severity that they lead to the extinction of its vital impulses and creative energy. This dooms the weaker system to obey and to accept the alien content and/or configuration. The explication of this concept in the global history is found in the Toynbeean system. Serving as a basic process of the Westernization (modernization) of nonEuropean nations, pseudomorphosis becomes a lot, drawn by the History itself.

The peculiarity of cultural genesis, that began in the New World, which was one of the first regions dragged into these processes, was that the cultural layers engaged and belonged to the extremums of the historical tensions, namelyArchaic and Modernity. Touching upon the roles that were played by the different participants, the role of the passive form fell to the autochthonous cultures, while the introduced active and dynamic form fell to the European culture. The latter, being a dominant force due to its historical consistency, dynamism, openness and plasticity with a distinctive rationality, focused around itself inner culture genesis forces, not finding and adequate response from the autochthonous culture. Autochthonous formation, conformed to the primary cultures of the Axial time (A. Weber) with their inherent conservatism, magicism, sacrality, self-absorption, mythological and religious consciousness, was non-dynamic historically and, therefore, acted as a countering measure to the European formation. The tumor, arising at the intersection of the two cultures, was a hybrid which was unable to move on to the synthesis stage. It was being stalled on the symbiotic aggregated states - transient in their nature.

For Europe, the process of transplanting its cultural forms into the New World was painless. However, for the New World, in the depths of which matured the tumor, the transplantation was a long and painful ordeal. The process, essentially, was not organic but mechanic in its nature, reduced to the literal implantation of alien cultural roots. The injury suffered by Latin America has left its mark on the region's whole cultural body in the form of fragmentation, juxtaposition of the original cultural and chronological sections, deformed ontological foundation.

The New World's culture genesis mechanics was also specified by the fact that the autochthonous culture served as a counter-tendency determining the non-linear character of the mentioned genesis. Despite the morphological consistency of European origin, survivability of which was ensured by the centrist paradigm, it showed some nonrigidity and fragility of own cultural framework in other geographic regions. The weakening of the genetically inherent structure and its ordering function was called by the Iberian stratum - a historical and cultural amalgam of Roman and Muslim origins that had set Iberian's eccentric character. The process of interaction among the cultural layers and counter-action of autochthonous culture strengthened that Iberian eccentricity. Thus, the ongoing process of culture genesis, without receiving an adequate compensation from any of the involved parties, accepted a non-linear development model with discontinuous form.

\section{Modes OF Not-BeING AND ENTITY OF BEING}

The chasms (rupturas)—zones, where the continuity of cultural traditions and historical periods fail, become the topos of (Latin) American culture formation. Its topological apparatus is being formed within the boundaries of the conceptual pair "being-not-being" with a clear preponderance of the latter. The tendency to negation, oblivion (el no-ser), is seen through a number of its refractions: "out / other-being" and related concepts of "groundless", "placelessness". The traced emphasis on the primacy of not-being sets negativist character to the emerging ontological paradigm. The very existence in it isn't being forced out and absorbed, but being retained by switching not-being modes into being ones. The whole process occurs within the boundaries (en las fronteras), where being and not-being characteristics reach balanced but unstable state forming thus a culture-forming energy release zone, captured by the notion of "emptiness / voidness" (vacío/vacuidad). Captured in that zone, opposing forces of being and not-being determine its marginal nature. Marginality serves as a constant influx of energy, confining the borderline character and specifying its maximal ontological tension. Under these conditions, the void is seen as the beginning of production (M.Heidegger), potentially containing anything, while its frame-"the space of encounters and transgressions" (F.Aínsa) — serves as the area of developing and generating new ontologies and sense.

In such a paradigm, the traditional axiomatics undergoes a notable conversion- the principle "ex nihilo nihil fit" ("nothing comes from nothing") transforms into "ex nihilo omnia fit" ("everything comes from nothing"). Axiological load gets redistributed. Thus, the negatively interpreted notbeing modes are filled with positive connotations as carrying a supply of culture-forming energy. Meanwhile, the latter, after receiving their existence, are not getting eliminated and completely overcome. They create instead the culture, infrastructure and, manifesting themselves as culture's negative traits, are recorded in a number of conceptual 
interpretations of ontological phenomena-emptiness / voidness, borderline / frontier.

In Latin American context, emptiness as a measure of existence finds its genetic bond to such category of uncertainty as randomness (accidentalidad). As a result, the ontological issues are found in continuous connection to the historic process, and, as a consequence, one defines the composition of conceptual apparatus in the form of such units as the "absence of", "shortage of", "scarcity of", insufficiency, or "deficiency".

The discovery of America is interpreted as casus imrpovisus. Just like any phenomenon having a cause of its occurrence in external circumstances (Europe, in particular), it seems to be historically accidental and, consequently, ontologically insufficient and defective. The roots of such ontological inferiority or insufficiency go into the polarity of chronological sections and the radical cultural heterogeneity of topology, which together represent a plurality of laminations with a hollow center, forming thus an ontological disintegration. In such a margin by its nature formation, the randomness enhances its ontological status. While turning into an existential notion, it radicalizes own ontological inferiority: not having an independent and selfsufficient existence. It can only exist only in "something else" ("en otra cosa"). Thus, it creates subordinate, dependent ties, which find its expression in the junction and adhesion and the attraction to ontologically complete and integral being. Balancing between being and not-being, randomness secures uncertain and unstable American "way of being", condemning the region to being in the Other / alien ("ser-en").

An accident, acting as a factor, influencing the historical process of American development, inevitably leads to deformation, giving rise to the distorted forms. A radical duality of American cultural background produces the inferiority of historical ground in the form of inability to have America's own genuine authentic story. Under such circumstances the lack of deep historical past forms a historical memory vacuum and, as a consequence, the awareness of the present without depth. In the mind of an American, the past is not permanent by its nature: it is neither absent nor present, constantly fluctuating, appearing and disappearing. In the historical time structure, this flickering past takes the position of "almost-absent-presence" ("presensia casi-ausente"). Formed this way, the complex of historical inferiority invocates a feeling of historical vulnerability. The relevance of the austere present with an unrooted past constitutes the "unhistoricity" (H.A.Murena). Securing itself as a defining characteristic of the American "way of being", the historical inferiority unfolds itself into modes of forsakenness and alienation. The heir to the dual cultural background - "son" of a European "father" and Indian "mother"- feels himself equally alien to both of his "parents", for him "the feeling of orphanhood is primer to the feeling of sonship" [11. P. 96]. In the described context, the void, acting as a symbol of the existential reality, manifests itself through the chasm.
In turn, the marginal nature of the borderline in a chronotopical cut defines it as a spatial-temporal transition and formation zone, manifesting such units as "out-being", transcendent, or "nowhere". At the existential level the state of transition-not-yet-being (no-ser-todavía) - is burdened with dramatics that gets its specification through rejection, denial, withdrawal, and escape.

Expectation (espectativa), keeping the existencial tension within the acceptable limits, serves as a catalyst of the borderline - "the zone of the boosted sensitivity" (F.Aínsa) [1. P. 51]. Through the modes of anticipation for change, the expectation reveals not-yet-being as something new-worldly, transforming the tension into thrust and commitment to labor Expectation reveals itself to be a fundamental ontological characteristic. Turning on the existential level into a project, it fills the gap between finding oneself in not-yet-being and still-being. As a certainty-position before the future-the expectation reveals itself to be a form of readiness, removing negation from not-being modus, transforming the not-yetbeing into pre-being state.

On an axiological level, the boundary is represented by Latin American living through its marginality in the context of semantic cultural field formation. Any given semiotic space requires the differentiation into two spaces: the inner one ("Us") and the external one ("Them") [6. P. 257]. In the mind of a culture carrier, this requires simultaneous retention and correlation of qualitatively different modes. Because of the unformed Latin American semiotic space, the mechanism of "retention and correlation" is weakened, so that the "Us" and "Them" correlation is being replaced by their juxtaposition. In turn, this causes the crave to fill the existential void by replacing "Our" with "Their" ("alien") semantic constants. The aforementioned replacement practice is initiated by a state of marginality, borderline, that specifies the selective character and determines criteria in search for ontological usefulness of the "Other". However, through this practice, not-yet-become "Our" undergoes debunking, get forgotten through self-abnegation, feels itself dissonant / mismatching, inauthentic. Marginality gets revealed as a kind of meaning-making source of (Latin) American culture: it determines the nature and form of culture's being, specializes the culture genesis process and sets the target direction-finding the existential fullness and revelation of (Latin) American essence - by cutting off side branches and limiting the fluctuation combinatorics.

The relevance of the borderline concept to the Latin American culture is ontologically supported by the disappearance of the center due to the displacement of the meaning-making mechanics from the inner space (the disembodied zone of voidness) to the marginalized surface. Marginality drags out a deep ontological tension previously found in a latent state. Captured by the borderline concept, the tension gets its existential landscape in form of a semantic basis of a number of cultural constants configurations, revealing thus the borderline as a zone of specified meanings.

Observed in (Latin) American context, correlation of ontological, epistemological, psychological and emotional 
orders encourages researchers to qualify "the enveloping voidness of borderline" [4. P. 208] as Latin American presymbol, through which the notions of spatial extent of Latin American culture is deployed; and "all the language forms of its validity" is read out [14. P. 337]; the subjective image of history is set. This allows us to continue with a typology of culture suggested by O. Spengler.

\section{IN SEARCH OF THE IDENTITY "FORMULA"}

America's kinship to European culture determined the formation of (Latin) American self-identity discourse. The expression of that is found in the perception of the European origin as an ideal- "how it should be" in virtue of its ontological completeness, wholeness, stability, identity and subsequent reception and assimilation of meanings, interpretative models and schemes representing European culture. The transposing of the European, in fact, geographically "alien", origin into "Our" living space, served as a form through which marginal (Latin) American culture clarified its own status and the status of the European cultural, historical and typological aspects. The process of cultural and the civilization's self-identification (autodeterminación) was lined up by fixing and articulating a mismatch between a real American existence and the American ideal model, through which activated the rationalization of "Otherness" of an American in relation to a European.

Ethno-racial and cultural fragmentation, being the result of La Conquista, had set own self-presentation and selfidentity strategy, inherent to the marginal culture. This led to the impossibility of direct transfer and net reproduction of European paradigms and constants in the American context, stimulating their subsequent (axiological) re-interpretation and transcoding. In turn, the methodological identification discourse arsenal was formed, and the idea of "America" was crystallized. In particular, structure-forming and central to European mentality concept of "Me" / "Self" turned out to be irrelevant to the American mentality, being replaced by "Us" notion ("nosotros"). This notion contains A.Roig's "I am I and the others" formula in a compact form. The formula, while expanding the European "Self" with the help of social dimension, sees the transition from individual identity to the collective one.

Through the "Us" conceptual idea, American identity comes to a homogenous state, overcoming the chaotic life structure-i.e. multi-layered historical and social realityyet keeping own marginality marked by miscegenation. After becoming a key unit of cultural dimension, "Us" serves as the invariant core of various self-identity designs, since the 17th and up till the 20th century. S. Bolivar proposed representative in this respect formula, stating "We are not Europeans; we are not Indians; we are but a mixed species of aborigines and Spaniards", "median species" ("especie media") [15. P.73]. Traced fixation and articulation concerning intermediacy should be viewed as a defining moment for understanding the Bolivarian formula. The formula itself seems to be incomplete: "American" is only opened in its authenticity, describing just the existential contours.
The strengthening and further development of "Us" idea is found in the conceptual works of J.Martí. His formula "Our America" ("nuestra América") constitutes American existential own order, specified in an inclusive model, suggesting the inclusion of heterogeneity and layering in itself. Following the logic "not only, but also...", Marti's formula acquires a universal character and comes out at the continental level: "Colored and white, Indians and Creoles"- that is America, described by J.Martí as "Our America" [9. P. 252].

The ability to connect heterogeneous, America accepts from the Spanish culture with its typical coexistence of different civilizations and time stages. This "eccentric break" [11. P. 17] assigned to America its cultural and historical singularity, opposing itself to North America, whose authentic order is built upon "eccentric lock" [11. P. 17], asserting isolation and exclusive opposition, set by "eitheror" logic. The "eccentric lock" model was inherent to the insular consciousness of the Anglo-Saxon culture and was used to describe the European culture at large.

American self-identity formula, proposed by J.Marti, reveals the sought-for existential fullness as polymorphic cultural modes. The historical inevitability of American consciousness is overcome and resolved-it orientates towards the European paradigm, but avoids getting built into it, absorbing it instead as one of the "Us" concepts.

\section{BINARITY AND PROJECTIVITY}

The cognitive apparatus of Latin American identity discourse specifies its initial finding between two possible self-identity models. This notion finds its expression in the presence of two binary oppositions, within which selfinterpretative models are arranged. Specific is not only the presence of the aforementioned oppositions (binary code is found within any cultural paradigm) but the content, representing their concepts and categories. The most representative in the context are those binary pairs, which are formed on the key lines of American culture-philosophical reflections-positivism and modernism. Those key lines enter-under the internal cultural order factors - complex conflict relations, which are reduced to ideological, culturephilosophical debates on the "entity" and prospect of an emerging American culture. In turn, it finds its theoretical expression in formulas "barbarism-civilization" (D.F. Sarmiento), “disharmony-harmony” (J. Martí).

In the mentioned binary opposition "barbarismcivilization", proposed by the positivists, the question of the mixed nature of the American culture is particularly acute. In that model, founded by the hard natural, biological and racial determinist theses, American miscegenation is interpreted as an ontological inferiority and, therefore, gets reduced to the concept of barbarism. The issue of overcoming said inferiority, i.e. getting rid of the "vicious diversity stain", is so extreme, so it comes to self-amputation-radical update of American population by the absorption of the undefiled progressive civilized blood. Emerged within that "barbarism-civilization" concept boundaries negativist connotation of the American miscegenation, causes a 
pessimistic racial-cultural "metaphysics" and fatalist national hypercriticism, denying any prospects of the nation's development [6. P. 15].

The polarity reversal of the self-identity scheme occurs in the Spanish-American modernism within the boundaries of "disharmony-harmony" binary opposition, which expands out of aesthetics and receives an ontological notion in the American context. American barbarian prime relates to disharmony that is recognized as existing and problematic but not as fatal and ontologically rooted. Disharmony is interpreted as the American "transition period" in which heterogeneous cultural and civilizational forms are symbiotic. The "transition period" may thus be interpreted as a number of oppositions: "inauthenticity-authenticity", "incompleteness - completeness", that reveal the American historical perspective - the need of self-actualization, finding own authentic and whole face.

America's search for own cultural identity is reduced to the problem of a harmonious person formation, who will vanquish existing ethnical, racial and cultural contradictions. For America, this means the transition to a historical phase, when symbiotic forms are replaced with the synthetic ones, healing heterogeneous battling notions. Synthesis, referential to the Spanish-American modernism, overcomes positivists' disbelief frequently expressed towards miscegenation, with an American person, revealing to be civilizational alternative one. From this point of view, the key positivists' concept of "barbarism-civilization" is being re-interpreted. The "barbarism" is declared to be imaginary, while the "civilization" is interpreted as the prospect of public selfmaking-i.e. the search for the own cultural and civilizational roots. The ideological platform for this search is reflected in J. Martí's thesis: "It is not enough just to be born-you must create yourself" ("No basta nacer-es preciso hacerse") [17. P. 41].

Dynamic understanding of synthesis, proposed by the Spanish-American modernism, reveals immanent to American self-identity discourse utopian orientation. Since synthesis is not the end but only the formation of a new quality, the path to the desired harmony, authenticity is seen as "a walk towards the undefined horizon of being" [6. P. 20]. Conceptualization of these ideas is found in a set of selfidentity constructs, that are formed within the SpanishAmerican modernism movement-"aerilism" / "latinity" (J.E. Rodó), "sovereign eclecticism" (R. Darío) — as well as outside of it in a more general Bolivarian tradition- "the fifth race" / "the cosmic race" (J. Vasconcelos).

In the search for organic self-identity forms, America's eclectic origin, seen as the initial base of its cultural and civilizational model, intensifies. At that, the future state of harmony is perceived as an example of global harmony and has a strong Universalist attitude. The peculiarity of an American historical experience is stressed, in particular, within an unprecedented racial and ethnic mix in the New World that introduced a powerful integration potency. It was granted a sense of universal unity. All of the mentioned allows to understand America as a continent, which is destined / promised to fulfill its mission on a planetary scale - "to be the axis of the future world", to ensure "the harmony of cultures" and times. Thus, emerged in the Spanish-American modernism idea that the "true is synthetic" (J.Martí), goes beyond actually American reality and is transferred into the global historical context, where, blending with the universal civilization, it marks the arrival of a new era, named "Universalism" (J. Vasconcelos).

\section{CONCLUSION}

The identification of the (Latin) American identity discourse's conceptual apparatus allows to reveal America not only as a complex cultural formation medium but also to identify the specifics of its identification apparatus by the initial historical and cultural circumstances. It is the latter that specifies the process of clarifying the existential foundations of the Latin-American world, which began with the count zero. Its expression is found in the emergence of two key identification line tendencies found in the continental cultural and philosophical reflections, positivism and modernism, that offered America its own way of gaining its cultural identity. These tendencies, typologically defined by non-existence and existence, create different content.

For positivists, America, marked by miscegenation, is marginal and conflict-inclined in its own nature and has no future. For them, America may find its own cultural identity only by standing the grounds of self-denial and hiding its original essence under the alien mask, dooming itself for "being-in" Other / alien.

The modernists, vice versa, claim ethno-cultural and ethno-racial diversity of America, its temporal multi-layering, to be a starting point for acquiring the sought self-identity. This viewpoint gets its conceptualization in institutionalizing ("creating a presence") the formula of "American Us", being transcribed as a perspective condition for self-creating America whose identity is based on its unity and distinction.

The implementation of the proposed projects, according to their authors, is only possible in a far future - in the New World (Nuevo Mundo), which gives their ideas somewhat utopian sounding. For positivists, it is a radical renewal of America (D.F. Sarmiento), i.e. the creation of a new race. For modernists, who, by contrast, do not deny the reality present and are hope-seized (esperanza) to achieve the completeness and harmony. The need to "withdraw the Indians from the state of inertia and stagnation" (J. Marti) prevents the implementation of their designs.

The analysis revealed the instability and mobility of the (Latin) American identity discourse's conceptual apparatus, which indicates the formation's incompletion and, as a consequence, the openness and transparency of the identity process on the ontological stage.

\section{REFERENCES}

[1] Aínsa F. Reconstructing Utopia. Essay.-M.: Nasledie-Éditions UNESCO, 1999. 
[2] Bondar O.Y. Building self-identity models: Latin American civilizational version. Part II // Bulletin of RUDN. "Philosophy" series.—№3.-2014.-P.120-134.

[3] Vaseiko E.A. The Concepts of Identity in Latin American Philosophy of the 1950s -1970s. Author's thesis, PhD in Philosophy.-M., 1994.

[4] Girin Y.N. The Poetics of Supertelicity: To Interpretation of Artistic Processes in Latin American Culture.-SPb.: Aletheia, 2008.

[5] Zemskov V.B. Latin America and Russia. The Problem of Cultural Synthesis in Borderline Civilizations. // ONS. - 2000. - №5.- P. 96-103.

[6] The History of Latin American Literatures. Vol. 3. The End of XIXThe Beginning of XX Century (1880s-1910s).-M.: Nauka, 1994.

[7] The History of Latin American Literatures. XX Century: 1920s-1990s. Vol. 4. Part 1.- M.: Nauka, 2004.

[8] Lotman Y.M. Semiosphere.-SPb: «Iskusstvo-SPb», 2000.

[9] Martí J. Selected.-M.: Khudozhestvennaja literatura, 1974.

[10] Pomeranz G.S. Culture Subecumenism Theory and the Identity Problem of Borderline Cultures // Exit Trance.- M.: Yurist, 1995.

[11] Paz O. Selected.-M.: Terra, 2001

[12] Shemyakin Y.G. Europe and Latin America: Interaction of Civilizations in World History Context.- M.: Nauka, 2001.

[13] Spengler O. The Decline of the West. Volume 1. Form and Actuality.-M.: Misl', 1998.

[14] Spengler O. The Decline of the West. Volume 2. Perspectives of World-History.-M.: Misl', 1998.

[15] Bolivar S. Doctrina del Libertador.-Caracas: Ed. Biblioteca Ayacucho, 1993.

[16] Andrade do Nascimento F. Fernando Aínsa. Del topos al logos: propuestas de Geopoética // ConNotas (Vol. V).—Núm.8.—2007.— P. 157-166.

[17] Martí J. Obras completas: Cuadernos apuntes. Vol. XXI.-La Habana: Editorial de Ciencias Sociales, 1991.

[18] Mayz Vallenilla E. El problema de América. Latinoamérica: cuadernos de cultura latinoamericana. Tomo 93.-México: Universidad Nacional Autónoma de México, 1979.

[19] Murena H.A. El pecado original de América.-Buenos-Aires: Fondo de Cultura Económica, 2006.

[20] Uranga E. Análisis del ser del mexicano.-México: Porrúa y Obregón, 1952. 